Proceeding Paper

\title{
Experimental Study on the Particle Flow and Validation of the Results Using TIS Model in a Continuously Operated Horizontal Fluidized Bed ${ }^{\dagger}$
}

\author{
Asad Ali ${ }^{1, *}$, Ghulam Abbas ${ }^{1}$, Khurram Shahzad Ayub ${ }^{1,2}$, Aiza Imran ${ }^{1}$, Liaqat Ali ${ }^{1}$ and Muhammad Zaid ${ }^{1}$ \\ 1 Department of Chemical Engineering, H.H Campus, University of Gujrat, Gujrat 50700, Pakistan; \\ engr.ghulamabbas@uog.edu.pk (G.A.); engr.khurram@uog.edu.pk (K.S.A.); aizaimran89@gmail.com (A.I.); \\ riskyrai2612@gmail.com (L.A.); zaidmuhammad650@gmail.com (M.Z.) \\ 2 State Environmental Protection Key Laboratory of Environmental Risk Assessment and Control on Chemical \\ Process, School of Resources and Environmental Engineering, East China University of Science and \\ Technology, Shanghai 200237, China \\ * Correspondence: asad.ali@uog.edu.pk \\ + Presented at the 1st International Conference on Energy, Power and Environment, Gujrat, Pakistan, \\ 11-12 November 2021
}

check for

updates

Citation: Ali, A.; Abbas, G.; Ayub,

K.S.; Imran, A.; Ali, L.; Zaid, M.

Experimental Study on the Particle

Flow and Validation of the Results

Using TIS Model in a Continuously Operated Horizontal Fluidized Bed. Eng. Proc. 2021, 12, 80. https:// doi.org/10.3390/engproc2021012080

Academic Editor: Ahsan Waseem

Published: 21 January 2022

Publisher's Note: MDPI stays neutral with regard to jurisdictional claims in published maps and institutional affiliations.

Copyright: (c) 2022 by the authors. Licensee MDPI, Basel, Switzerland. This article is an open access article distributed under the terms and conditions of the Creative Commons Attribution (CC BY) license (https:// creativecommons.org/licenses/by/ $4.0 /)$.

\begin{abstract}
The particle residence time in a gas-solid fluidized bed is of great interest. In this work, experiments have been carried out to investigate particle transportation, which is a matter of concern especially in pharmaceuticals, agriculture, food, and many other industries where time is the major concern, which effects the product quality. By varying the feed rate and baffle gap height in this research, the dispersion coefficient decreases significantly, which reduces the back-mixing and number of tanks as well. Moreover, the obtained results were validated with the tank in series (TIS) model.
\end{abstract}

Keywords: fluidized bed; residence time distribution; tank in series model; feed rate; baffle gap height; method of moments

\section{Introduction}

The control of the particle-mixing process in the reactor is crucial for the design and operation of gas-solid reactors due to its vital role in maximizing the profitability [1] Therefore, the Residence Time Distribution (RTD) of particles has a great impact on product quality in many industrial processes; e.g., in the drying process, if a product is achieved before its optimum time, it still has some unwanted moisture. However, if it exits the system after its optimum time, it could be deteriorated [2]. The drying rate has a close relationship with mean residence time and the dispersion coefficient; regarding this, researchers worked on a continuous fluidized bed by varying parameters such as solid feed rates, weir height, and inlet solid moisture content [3,4]. Moreover, some scientists have worked on particle mixing in a continuous fluidized bed and they observed that the bed appearance seems to be more homogeneous at higher gas velocities, and the dispersion coefficient also increases with increasing bed height due to the excess air velocity [5,6]. According to the literature review, several authors have attempted to find the RTD and dispersion coefficient by using different techniques and by varying parameters of the fluidized bed, but further work is still required to reach a particular conclusion. The present paper aims to examine the particle RTDs from the experimental data by varying the baffle gap height and solid feed rate.

\section{Experimental Procedure}

The experiments were performed by using the material and tracer particles of $\gamma_{-} A_{2} \mathrm{O}_{3}$, with a particle size of $1.8 \mathrm{~mm}$ in diamter. The tracer particles were usually injected directly into the bed using a pulse technique [7]. The number of tracer particles in each experiment was $500 \mathrm{~g}$. First of all, three baffles were installed into the processing chamber, with a gap 
height of $0.4 \mathrm{~cm}$ from the distributor plate. After that, the process was started by turning on the blower and rotary feeders. The airflow rate was maintained constant throughout the experiment at $1400 \mathrm{~m}^{3} / \mathrm{h}$. The samples were analyzed in the laboratory with the help of a rotary cone sample divider and vibratory feeder. The same procedure was repeated for the feed rates of 1.0 and $1.5 \mathrm{~kg} / \mathrm{min}$ by varying the gap height of the baffles i.e., 0.6 or $1.2 \mathrm{~cm}$.

\section{Results and Discussion}

In this section, results of all the RTD experiments are displayed in Table 1. The investigated parameters are the solid feed rate and baffle gap height.

Table 1. The operating parameters and results of the RTD experiments.

\begin{tabular}{ccccccccccc}
\hline \multirow{2}{*}{ Run } & $\mathbf{F . R}$ & $\mathbf{G . H}$ & $\mathbf{M}_{\mathbf{p r o}}$ & $\mathbf{M}_{\mathbf{h}}$ & $\overline{\boldsymbol{t}}$ & $\boldsymbol{\sigma}^{\mathbf{2}}$ & $\sigma_{\boldsymbol{\theta}}^{2}$ & $\mathbf{B O}$ & $\mathbf{D} \times \mathbf{1 0}^{-\mathbf{4}}$ & $\mathbf{N}$ \\
\cline { 2 - 10 } & $\mathbf{k g} / \mathbf{m i n}$ & $\mathbf{c m}$ & $\mathbf{k g}$ & $\mathbf{k g}$ & $\mathbf{s}$ & $\mathbf{s}^{\mathbf{2}}$ & - & - & $\mathbf{m}^{\mathbf{2}} / \mathbf{s}$ \\
\hline 1 & 0.5 & 0.4 & 30.183 & 8.407 & 938 & $43,879,203$ & 0.4986 & 2.56 & 4.149 & 2.0053 \\
2 & 1.0 & 0.4 & 32.164 & 9.638 & 563 & $140,052.49$ & 0.4415 & 3.15 & 5.62 & 2.2648 \\
3 & 1.5 & 0.4 & 43.063 & 9.765 & 350 & $42,313.89$ & 0.3455 & 4.53 & 6.30 & 2.8942 \\
4 & 0.5 & 0.6 & 17.382 & 8.799 & 785 & $245,469.05$ & 0.3981 & 3.709 & 3.434 & 2.5114 \\
5 & 1.0 & 0.6 & 28.917 & 9.041 & 544 & $142,297.97$ & 0.4870 & 2.679 & 6.906 & 2.053 \\
6 & 1.5 & 0.6 & 44.068 & 9.933 & 398 & $70,424.91$ & 0.4431 & 3.137 & 7.995 & 2.256 \\
7 & 0.5 & 1.2 & 15.014 & 8.843 & 695.8 & $201,334.77$ & 0.4157 & 3.47 & 4.14 & 2.405 \\
8 & 1.0 & 1.2 & 30.285 & 9.556 & 463 & $130,478.44$ & 0.6070 & 1.72 & 12.501 & 1.647 \\
9 & 1.5 & 1.2 & 40.887 & 9.297 & 402 & $82,877.70$ & 0.5117 & 2.458 & 10.11 & 1.953 \\
\hline
\end{tabular}

\subsection{Effect of Solid Feed Rate on Dispersion Coefficient and Bodenstein Number}

The dispersion coefficient is a very important characteristic number for consideration that represents the spreading process and it also gives information about back-mixing. Figure 1a presents the relationship between the dispersion coefficient and the feed rate for constant baffle gap heights. The graph shows that the dispersion coefficients increase with an increasing feed rate for the cases of $0.4,0.6$, and $1.2 \mathrm{~cm}$. Furthermore, it was also observed that the Dispersion Coefficient has the lowest value by using a lower baffle gap height i.e., $0.4 \mathrm{~cm}$.
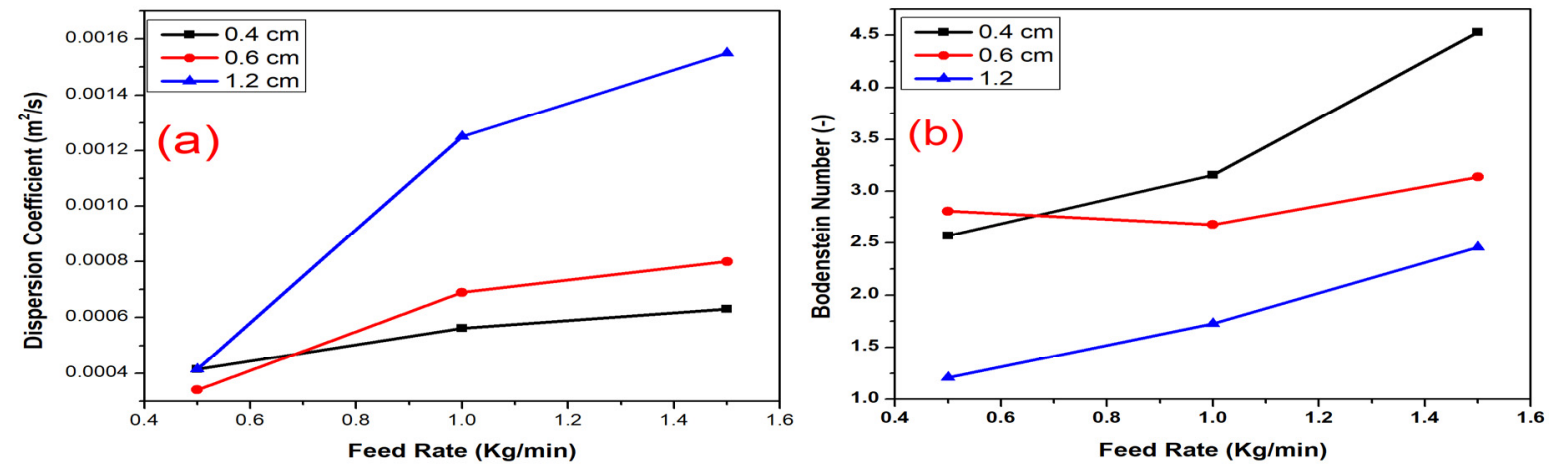

Figure 1. The effect of solid feed rate on (a) dispersion coefficient and (b) Bodenstein Number.

Figure $1 \mathrm{~b}$ shows the relation of Bodenstein's number with the solid feed rate. The Bodenstein number is one of the more important characteristic numbers for studying the behavior of particles with respect to RTD. It is a ratio between convective transport and dispersive transport of particles in the system. The Bodenstein number increasing tells us that the convective moment is dominant and particles move in a forward direction, whereas if the Bodenstein number decreases, it shows that particles are more dispersive. It can be seen from Figure $1 b$ that the Bodenstein number increases when baffles are installed and the feed rate is increased for the case of baffle gap heights of $0.4,0.6$, and $1.2 \mathrm{~cm}$. 


\subsection{Effect of Baffle Gap Height on Dispersion Coefficient and Bodenstein Number}

Figure 2a shows that the dispersion coefficient increases with an increase of the baffles gap height for the cases of $1 \mathrm{~kg} / \mathrm{min}$ and $1.5 \mathrm{~kg} / \mathrm{min}$. wherever for the case of $0.5 \mathrm{~kg} / \mathrm{min}$, the dispersion coefficient initially exhibits a declining trend with an increase in the gap height from $0.4 \mathrm{~cm}$ to $0.6 \mathrm{~cm}$. However, a further increase in the gap height from $0.6 \mathrm{~cm}$ to $1.0 \mathrm{~cm}$ exhibits a slight increasing trend. The results tell that the dispersion coefficient increases with an increase in baffle gap height. The results are as per expectations, as some researchers had worked on this issue previously and found the same results $[5,8]$. Figure $2 b$ depicts the declining trend of the Bodenstein number while the gap height increases.
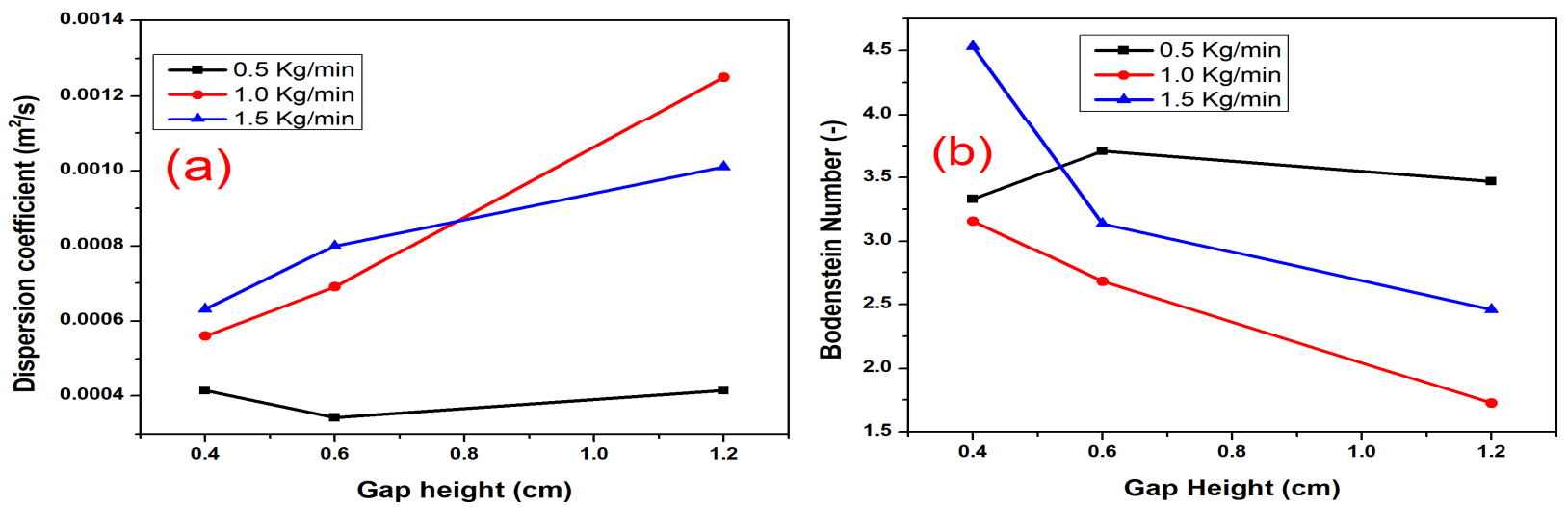

Figure 2. The effect of gap height on (a) dispersion coefficient and (b) Bodenstein number.

\section{Analysis with Tank in Series Model}

It can be observed that out of the 12 graphs, the curves of 9 experiments fit with the tank in series model very well, while 3 of them have irregular behavior. As can be seen from Figure $3 a, b$, the curve from experiment results fits so well with the tank in series model curve because of the mass balance.
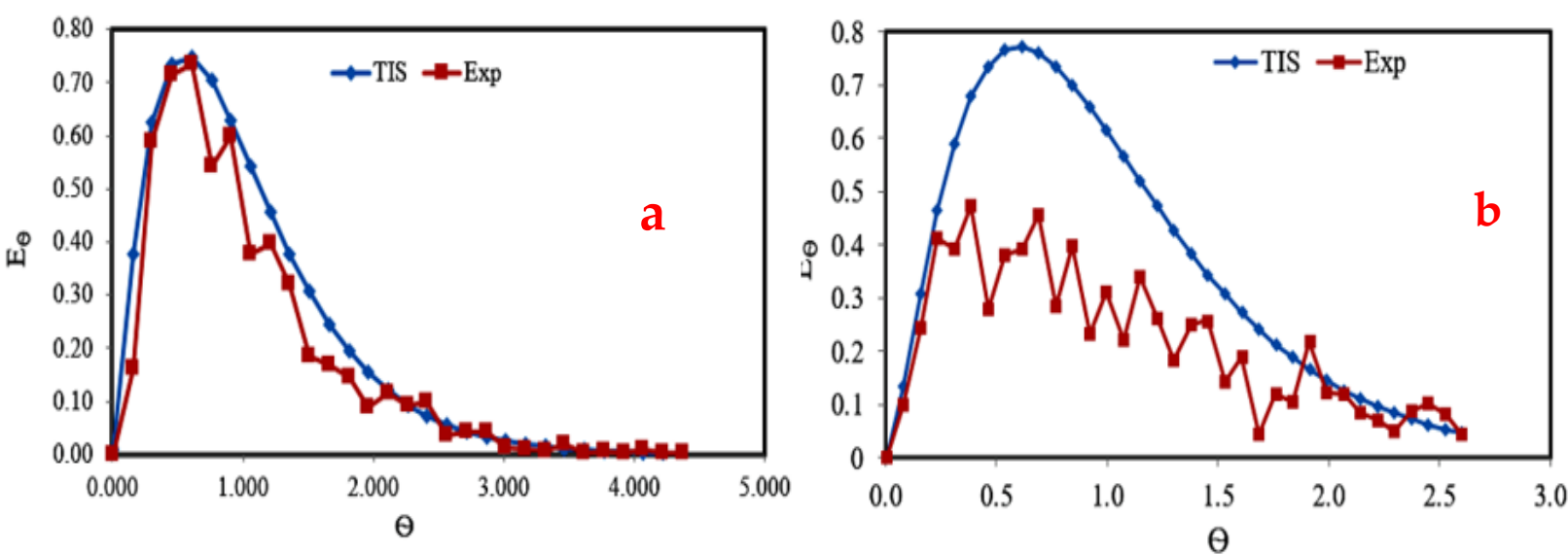

Figure 3. Comparison of experimental results with TIS Model: (a) Run \# 6; (b) Run \# 4.

\section{Conclusions}

The dispersion coefficient and the Bodenstein number are the most important characteristic numbers for studying the RTD in horizontal fluidized beds. By introducing parameters such as feed rate and baffle gap height, the back-mixing of the particles decreases and the particles can thereby be better controlled. Furthermore, the tank in series model was also used to investigate the behavior of these fluidized beds and the result fit with the model very well. The relations between the number of the tanks, the dispersion coefficient, and the Bodenstein number are also established in this study. 
Institutional Review Board Statement: Not applicable.

Informed Consent Statement: Not applicable.

Data Availability Statement: Not applicable.

Conflicts of Interest: The authors declare no conflict of interest.

\section{References}

1. Hua, L.; Wang, J. Residence time distribution of particles in circulating fluidized bed risers. Chem. Eng. Sci. 2018, 186, 168-190. [CrossRef]

2. Bachmann, P.; Tsotsas, E. Analysis of residence time distribution data in horizontal fluidized beds. Procedia Eng. 2015, 102, 790-798. [CrossRef]

3. Srinivasakannan, C.; Al Shoaibi, A.; Balasubramanian, N. Continuous fluidized bed drying with and without internals: Kinetic model. Chem. Biochem. Eng. Q. 2012, 26, 97-104.

4. Khanali, M.; Rafiee, S.; Jafari, A.; Banisharif, A. Study of residence time distribution of rough rice in a plug flow fluid bed dryer. Int. J. Adv. Sci. Technol. 2012, 48, 103-114.

5. Avidan, A.; Yerushalmi, J. Solids mixing in an expanded top fluid bed. AIChE J. 1985, 31, 835-841. [CrossRef]

6. Borodulya, V.; Epanov, Y.G.; Teplitskii, Y.S. Horizontal particle mixing in a free fluidized bed. J. Eng. Phys. 1982, 42, 528-533. [CrossRef]

7. Levenspiel, O. Tracer Technology: Modeling the Flow of Fluids; Springer Science \& Business Media: New York, NY, USA; Dordrecht, The Netherlands; Heidelberg, Germany; London, UK, 2011; Volume 96.

8. Satija, S.; Zucker, I. Hydrodynamics of vibro-fluidized beds. Dry. Technol. 1986, 4, 19-43. [CrossRef] 